\title{
A set of SCAR markers in cluster bean (Cyamopsis tetragonoloba L. Taub) genotypes
}

\author{
Pratibha Sharma $^{1}$, Vinod Kumar ${ }^{2 *}$ K. Venkat Raman' ${ }^{2}$ Kapil Tiwari ${ }^{2}$ \\ ${ }^{1}$ Department of Bioscience \& Biotechnology, Banasthali University, Rajasthan, India \\ ${ }^{2}$ National Research Center on Plant Biotechnology, IARI, New Delhi, India \\ Email: ${ }^{*}$ kumar.vinod81@gmail.com
}

Received 11 October 2013; revised 21 December 2013; accepted 9 January 2014

Copyright (c) 2014 Pratibha Sharma et al. This is an open access article distributed under the Creative Commons Attribution License, which permits unrestricted use, distribution, and reproduction in any medium, provided the original work is properly cited. In accordance of the Creative Commons Attribution License all Copyrights (c) 2014 are reserved for SCIRP and the owner of the intellectual property Pratibha Sharma et al. All Copyright (c) 2014 are guarded by law and by SCIRP as a guardian.

\section{ABSTRACT}

Cluster bean, one of the most important cash legume crop has played an increasingly important role in wide range of industries. Owing to the significance of molecular marker studies in numerous applications including in genetic improvement of crops, there is an obvious need to undertake such studies in cluster bean. In the present work, 35 genotypes of cluster bean were collected from different states of India and analyzed using RAPD and ISSR markers. Further SCAR marker system was introduced in order to increase the reproducibility of the polymorphism and specificity. For this polymorphic (RP-3, 1000 bp; RP-19, 1250 bp and 1100 bp) and geographical specific bands (RP-9, 650 bp) from RAPD as well as genotype specific band (IS-8, 550 bp) from genotype RGC-1031 (Rajasthan) from ISSR were selected and converted into SCAR markers. The study revealed first set of sequence-based SCAR markers in cluster bean which found more specific information using RAPD and ISSR profiles. One genotype specific SCAR-20 for RGC-1031 (tolerant genotype against Macrophomina phaseolina), could be used to prove identity of the genotype for improvement as well for its genetic purity assessment. Another SCAR-8 was selected due to its specificity for cluster bean genotypes from Rajasthan which might be important for population admixture studies.

\section{KEYWORDS}

Cluster Bean; ISSR; RAPD; SCAR

${ }^{*}$ Corresponding author.

\section{INTRODUCTION}

Cluster bean (Cyamopsis tetragonoloba L. Taub) commonly known as guar is a native plant of India principally grown for its green fodder and pods that are used for food and feed. Cluster bean is grown mainly in India, Pakistan, United States, Sudan, South Africa, Brazil, Malawi, Zaire and also in some parts of Australia [1]. India is a major producer of cluster bean and contributes to $80 \%$ of the world's total production of cluster bean [2], which is 7.5 to 10 lakh tonne annually. In India, Rajasthan alone contributes $70 \%$ of India's total production.

Cluster bean is a cash crop for its application in textile, paper, petroleum, mining, pharmaceuticals, explosives, and food industries because of its galactomannan rich endosperm. Particularly last year, world demand for guar gum has skyrocketed and the price of guar has increased by approximately $230 \%$ and even more, mainly because of increased oilfield shale gas demand. As a consequence, there has been a 75\% jump in exports from India [3]. The increasing demand of this seed crop cannot be compensated by present resources available for cluster bean improvement. Most of the farmers from tropical areas grow it as a secondary crop because of its low production and productivity. New varieties with higher yield, disease/ insect/pests resistant, higher seed quality, larger seed size and high gum content are urgently needed. Therefore, paramount efforts are required to improve yield and gum quality of cluster bean using conventional and biotechnological approaches.

India conserves an enormous wealth of cluster bean (2969 accession, NBPGR, Jodhpur) [4] along with a wide variability in morpho-physiological [2,5] characteristics. Biochemical marker studies using allozyme have been carried out in the past [6] in cluster bean. On the 
contrary, very limited breeding work has been done and very little attention has been given to its genetic improvement in the past in order to enhance the productivity levels of cluster bean.

Owing to unavailability of sequence based molecular markers in some of the orphan crops, RAPD and ISSR are the markers of choice. In such crops, RAPD and ISSR have been widely used in the genotype identification, genetic mapping and marker-assisted selection of plants, due to their simplicity, low cost and lower infrastructure requirements. These markers have been extensively used for identifying relationships at the cultivar and species level $[7,8]$. Although reproducibility is a major concern in such markers [9], they explore the whole genome and sometime generate information which might be of interest for molecular breeders such as amplicons co-segregates with a particular trait or an amplicon specific for a particular genotype.

Such markers could be converted into sequence-characterized amplified region (SCAR) markers [10]. Compared to arbitrary primers, SCARs exhibit several advantages in mapping studies, map based cloning as they can be used to screen pooled genomic libraries by PCR, physical mapping, locus specificity, etc. SCARs also allow comparative mapping or homology studies among related species, thus making it an extremely adaptable concept. In the past, SCARs has been widely applied in studies on genetic diversity $[11,12]$, gene tagging $[13,14]$ and genome mapping [15,16]. Among molecular markers only RAPD has been used for genetic variability analysis in cluster bean [17-19]. To best of our knowledge, no work has been reported on sequence based marker for characterization of cluster bean genotypes. Hence, in the present investigation, an attempt has been made at synthesizing SCARs from RAPD and ISSR markers in cluster bean.

\section{MATERIALS AND METHODS}

\subsection{Collection of Seeds}

Total 35 cluster bean genotypes were collected from six major guar growing states for this study viz. Gujarat,
Haryana, Madhya Pradesh, Punjab, Rajasthan and Uttar Pradesh (Table 1). These were grown in green house and healthy leaves were collected for the extraction of DNA.

\subsection{DNA Isolation}

DNA was extracted from healthy leaves of all genotypes using the CTAB method of Doyle and Doyle [20] with slight modifications. Its integrity was checked on $0.8 \%$ agarose gel electrophoresis. Purified DNA was measured using Nano Drop (Nano Drop ND-1000 Version 3.1.1). After quantification, the DNA was diluted with TE buffer (Tris-10 mM and EDTA-1 mM, pH 8.0) to a working concentration of $25 \mathrm{ng} / \mu \mathrm{l}$ for PCR analysis.

\subsection{RAPD and ISSR Analysis}

For RAPD and ISSR analysis, only those primers were selected which showed reproducible and contrasting amplification patterns. Using this scale, finally 20 RAPD primers out of 40 and 10 ISSR primers out of 30 were selected for the diversity analysis of the current set of cluster bean genotypes.

The RAPD and ISSR-PCR reaction were performed in a $25 \mu$ reaction mixture containing $50 \mathrm{ng}$ of template DNA, $0.2 \mathrm{mM}$ dNTPs, 1X Taq buffer with $1.5 \mathrm{mM}$ $\mathrm{MgCl}_{2}, 1 \mathrm{U}$ Taq DNA polymerase and 6 pmol of each primer. PCR amplification was performed in thermal cycler (PEQLAB, Germany) using the following amplification profile; initial denaturation of template DNA at $94^{\circ} \mathrm{C}$ for $4 \mathrm{~min}$ followed by 44 amplification cycles of denaturation at $94^{\circ} \mathrm{C}$ for 1 min primer annealing at $37^{\circ} \mathrm{C}$ (RAPD) and $52^{\circ} \mathrm{C}-62^{\circ} \mathrm{C}$ (ISSR) for $1 \mathrm{~min}$ and elongation at $72^{\circ} \mathrm{C}$ for 2 min followed by a final extension step at $72^{\circ} \mathrm{C}$ for $5 \mathrm{~min}$. The PCR products of both RAPD and ISSR were resolved by electrophoresis on $1.5 \%$ agarose gels with $1 \times$ TBE buffer stained with ethidium bromide $(0.5 \mu \mathrm{g} / \mathrm{ml})$ and photographed under UV light inside gel documentation system (Biorad).

\subsection{Data Analysis}

The RAPD and ISSR data were analyzed using NTSYS-

Table 1. Different genotypes of cluster bean collected from various states of India.

\begin{tabular}{cc}
\hline States & Genotypes \\
\hline Rajasthan & RGC-197, RGC-936, RGC-986, RGC-1002, RGC-1003, RGC-1031, RGC-1017, \\
RGC-1053, RGC-1066, RGC-1030, RGM-111, RGM-112, RGM-115, Bundel guar \\
Haryana & HG-365, Priya-151, HG-353, HG-563, HG-75, HG-890, FS-22 \\
Gujarat & Swati-55, Jyoti-555, Parasiya, Guara-80 \\
Uttar Pradesh & Pusa-Navbhar, Amul-51, Neelam-51, PNB, Krishna \\
Punjab & Jyoti-55, Local-selection, Ageta-111 \\
Madhya Pradesh & Pusa Selection I, Pusa Sadabhar \\
\hline
\end{tabular}


PC software version 2.2 e [21]. The discrimination power $\left(D_{j}\right)$ was calculated to find out the efficiency of the random primers to distinguish between individuals [22].

\subsection{Cloning and Sequencing of RAPD/ISSR Fragment}

The target DNA fragments in the RAPD and ISSR reactions were extracted from agarose gels using the Nucleopore Gel Extraction kit (Genetix Biotech Asia Pvt. Ltd). The fragments were cloned into the pGEM-T easy vector (Promega). E. coli DH5 $\alpha$ competent cells were transformed with the recombinant vector and were then plated onto LB agar-ampicillin-IPTG-X-gal plates. Positive colonies were determined by blue/white screening. Plasmids from randomly selected white colonies were extracted using the QIA mini preparation kit (Qiagen). Restriction digestion with EcoRI was conducted to confirm the size of the inserted fragment. The plasmids containing the fragments of the correct size were sequenced with ABI Big Dye Terminator Cycle Sequencing Kit (Applied Biosystem) in ABI PRISM ${ }^{\circledR} 3730$ automated sequencer using M13 forward or M13 reverse primer.

\subsection{SCAR Primer Designing and Validation}

Based on the sequence of cloned RAPD and ISSR markers, specific primer pairs were designed using Primer 3 software and synthesized by Integrated DNA Technologies (IDT, USA). PCR amplification was carried out with all 35 genotypes of cluster bean using 5 pmol of each SCAR primer (forward and reverse), $1 \times$ PCR buffer with $1.5 \mathrm{mM} \mathrm{MgCl}_{2}, 0.2 \mathrm{mM}$ dNTP mix, 1 U Taq DNA polymerase and 25 ng template DNA in $10 \mu$ reaction volume. The amplification cycle consisted of an initial denaturation at $94^{\circ} \mathrm{C}$ for 4 min followed by 35 cycles of 1 $\min$ at $94^{\circ} \mathrm{C}, 1 \mathrm{~min}$ at according to $\mathrm{Tm}$ of each primer, and 2 min at $72^{\circ} \mathrm{C}$, and finally terminated with an extension of $5 \mathrm{~min}$ at $72^{\circ} \mathrm{C}$. The annealing temperature was adjusted according to the Tm of the primers.

\section{RESULTS}

In present study 35 cluster bean genotypes were characterized using RAPD, ISSR and SCAR markers. All the DNA-based markers were found efficient for diversity analysis of cluster bean genotypes. The study also revealed first set of sequence-based SCAR markers.

\subsection{RAPD and ISSR Analysis}

In RAPD analysis, a total of 164 amplicons were obtained with an average of 8.2 bands/primer which ranged in size from 220 to $2050 \mathrm{bp}$. Total bands ranged from 3 (RP-15) to 13 (RP-44). Of the 164 amplified bands, 147 were polymorphic with an average of $90.30 \%$ polymor- phism which ranged from 57.1\% (RP-42) to 100\% (11 primers). Only 2 out of 20 primers showed less than $75 \%$ polymorphism (Table 2). Jaccard's similarity coefficients among all pair-wise combinations of accessions ranged from 0.38 to 0.91 with a mean genetic similarity of 0.69 . Dendrogram clustered all the genotypes into 9 main groups on the basis of cut-off value of Jaccard's similarity coefficient.

A total of 105 band positions were obtained using 10 ISSR primers. The number of scorable markers produced per primer ranged from 7 to 17 and the size of amplified products ranged from $450 \mathrm{bp}$ to $3500 \mathrm{bp}$. Out of 105 band positions, 102 were found to be polymorphic with $97 \%$ of polymorphism (Table 3). The results showed that polymorphism index varied from $77.7 \%$ to $100 \%$ for different primers. The highest polymorphism was observed with primer IS-8, IS-14 and IS-18 while it was found minimum for primer IS-6. ISSR-based genetic similarity coefficients among all pair-wise combinations were ranged between 0.20 and 0.88 with a mean value of 0.61 . The ISSR-based dendrogram clustered all the genotypes into 7 groups using average similarity coefficient as cut-off value.

Primers produced maximum unique banding patterns were considered as efficient RAPD primers in distinguishing all the genotypes. A band of $1000 \mathrm{bp}$ from RAPD primer RP-3 was found highly polymorphic with good reproducibility (Figure 1). In another case, two bands (1100 bp and 1250 bp) from RAPD primer RP-19 were also found highly polymorphic (Figure 2). The RAPD primers also accounted for bands present only in a set of genotypes from a particular region. In this perspective, a band of 650 bp from RAPD primer RP-9 showed its presence only in some genotypes of Rajasthan (Figure 3). The ISSR primer IS-8 produced one specific band (550 bp) position for a genotype of Rajasthan (RGC-1031) (Figure 4).

\subsection{SCAR Analysis}

For SCAR marker polymorphic, geographical specific as well as genotype specific bands were selected. Among 20 RAPD primers, primer RP-3 produced polymorphic band of size $1000 \mathrm{bp}$. Similarly primer RP-19 produced 2 polymorphic bands of size 1250 bp (genotype RGC-936) and 1100 bp (genotype RGC-1003) respectively. Primer RP-9 produced distinct band (650 bp) among genotypes of Rajasthan. Similarly one specific band (550 bp) from genotype RGC-1031 (Rajasthan) amplified using through ISSR primer was eluted for conversion into SCAR marker (Table 4).

The recombinant plasmids after cloning into E. coli DH5 $\alpha$ competent cells using pGEM-T easy vector were selected with accurate size of insert after restriction digestion (Figure 2) and sequenced in triplicate for each 
Table 2. Total number of amplified fragments and number of polymorphic fragments generated by PCR using selected random decamers in 35 genotypes of cluster bean.

\begin{tabular}{|c|c|c|c|c|c|c|}
\hline Primer & Sequence (5’-3’) & Total bands & No. of polymorphic bands & \% Polymorphism & $\begin{array}{l}\text { Range of fragment } \\
\text { size (bp) }\end{array}$ & $\begin{array}{c}\text { Discrimination } \\
\text { power (Dj) }\end{array}$ \\
\hline RP-2 & TGCCGAGCTG & 9 & 9 & 100 & $450-1900$ & 0.8 \\
\hline RP-3 & TGACCCCTCC & 9 & 7 & 77.7 & $250-2025$ & 0.98 \\
\hline RP-5 & AGGGGTCTTG & 7 & 6 & 85.7 & $475-1350$ & 0.65 \\
\hline RP-7 & GAAACGGGTG & 9 & 9 & 100 & $450-1400$ & 0.94 \\
\hline RP-8 & GTGACGTAGG & 4 & 4 & 100 & $250-1200$ & 0.71 \\
\hline RP-9 & CCGTCATTGG & 9 & 9 & 100 & $350-3000$ & 0.95 \\
\hline RP-10 & GTGATCGCAG & 12 & 11 & 91.6 & $350-1580$ & 0.92 \\
\hline RP-13 & CACCACССАС & 10 & 6 & 60 & $250-1900$ & 0.4 \\
\hline RP-15 & TTCCGAACCC & 3 & 3 & 100 & $850-1000$ & 0.4 \\
\hline RP-19 & CAGGCGGCGT & 5 & 5 & 100 & $550-1000$ & 0.87 \\
\hline RP-42 & AGTAGGGCAC & 7 & 4 & 57.1 & $250-930$ & 0.11 \\
\hline RP-44 & GGACGCTTCA & 13 & 12 & 92.3 & $250-1900$ & 0.95 \\
\hline RP-45 & GGGTAACGTG & 5 & 4 & 80 & $300-1700$ & 0.41 \\
\hline RP-46 & AGTGCAGCCA & 12 & 10 & 83.3 & $450-1375$ & 0.85 \\
\hline RP-48 & AGGGTGGGTG & 11 & 11 & 100 & $250-1350$ & 0.91 \\
\hline RP-51 & GGGACGATGC & 10 & 8 & 80 & $350-1580$ & 0.88 \\
\hline RP-54 & AGTGCGCTGA & 9 & 9 & 100 & $250-2000$ & 0.88 \\
\hline RP-55 & CCGCGTCTTG & 6 & 6 & 100 & $250-1450$ & 0.75 \\
\hline RP-57 & CCCCGAAGGT & 6 & 6 & 100 & $450-2025$ & 0.49 \\
\hline \multirow[t]{3}{*}{ RP-59 } & GGCTAACCGA & 8 & 8 & 100 & $250-1580$ & 0.68 \\
\hline & Total & 164 & 147 & & & \\
\hline & Average & 8.2 & 7.35 & 90.3 & & 0.72 \\
\hline
\end{tabular}

Table 3. Total number of amplified fragments and number of polymorphic fragments generated by PCR using ISSR primers in 35 genotypes of cluster bean.

\begin{tabular}{|c|c|c|c|c|c|c|c|}
\hline Primer & Sequence & $\operatorname{Tm}\left({ }^{\circ} \mathrm{C}\right)$ & Total bands & No. of polymorphic bands & \% Polymorphism & $\begin{array}{c}\text { Range of fragment } \\
\text { size (bp) }\end{array}$ & $\begin{array}{c}\text { Discrimination } \\
\text { power (Dj) }\end{array}$ \\
\hline IS-5 & $(\mathrm{AG})_{8} \mathrm{~T}$ & 50 & 8 & 8 & 100 & $560-3500$ & 0.86 \\
\hline IS-6 & $(\mathrm{AG})_{8} \mathrm{C}$ & 52 & 9 & 7 & 77.7 & $600-1800$ & 0.85 \\
\hline IS-7 & $(\mathrm{GA})_{8} \mathrm{~T}$ & 50 & 17 & 17 & 100 & $560-3500$ & 0.96 \\
\hline IS-8 & $(\mathrm{GA})_{8} \mathrm{C}$ & 52 & 13 & 13 & 100 & $650-3500$ & 0.99 \\
\hline IS-14 & $(\mathrm{GT})_{8} \mathrm{C}$ & 54 & 5 & 5 & 100 & $1000-3000$ & 0.84 \\
\hline IS-19 & $(\mathrm{AC})_{8} \mathrm{~T}$ & 50 & 7 & 7 & 100 & $500-3000$ & 0.44 \\
\hline IS-20 & $(\mathrm{AC})_{8} \mathrm{C}$ & 54 & 13 & 12 & 92.3 & $564-3000$ & 0.94 \\
\hline IS-21 & $(\mathrm{AC})_{8} \mathrm{G}$ & 54 & 13 & 13 & 100 & $450-2800$ & 0.98 \\
\hline IS-23 & $(\mathrm{TG})_{8} \mathrm{C}$ & 52 & 12 & 12 & 100 & $700-3000$ & 0.97 \\
\hline \multirow[t]{3}{*}{ IS-25 } & $(\mathrm{AGC})_{6}$ & 60 & 8 & 8 & 100 & $564-2500$ & 0.78 \\
\hline & Total & & 105 & 102 & & & \\
\hline & Avg. & & 10.5 & 10.2 & 97 & & 0.86 \\
\hline
\end{tabular}




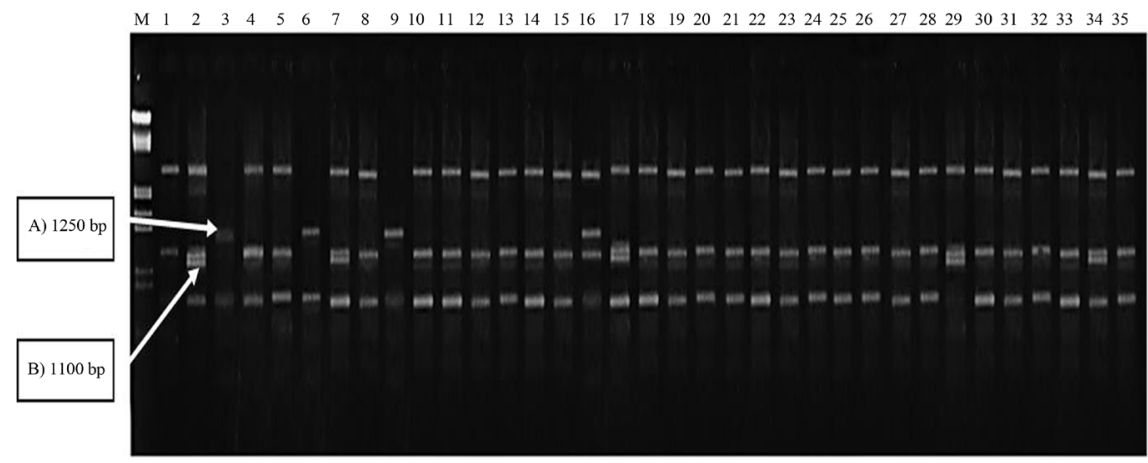

(a)

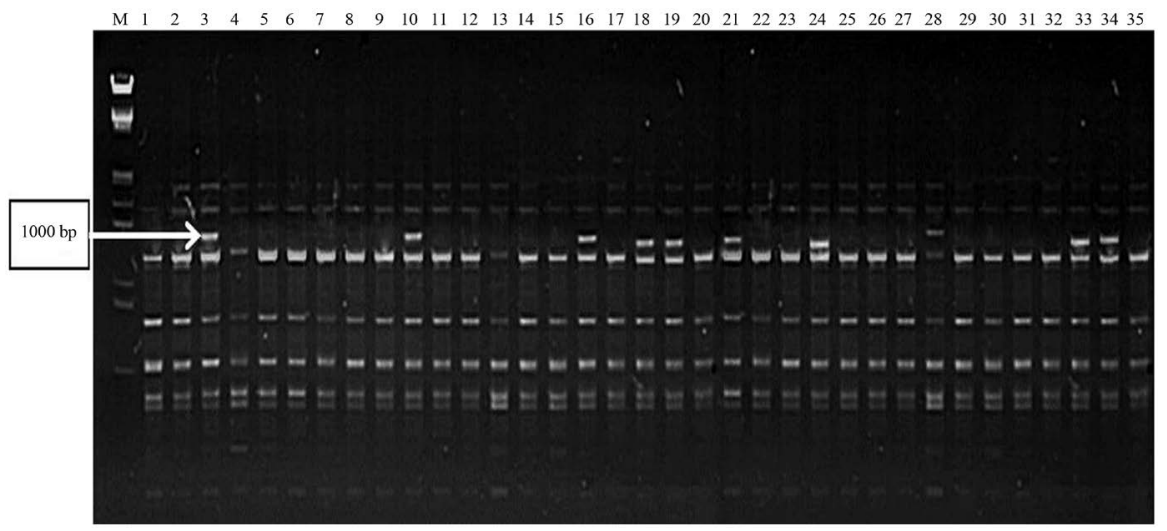

(b)

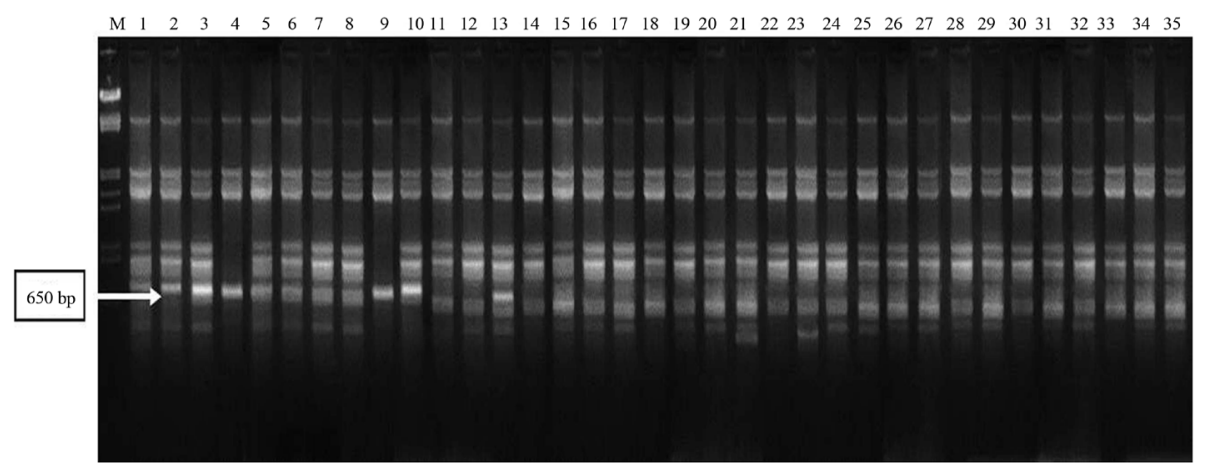

(c)

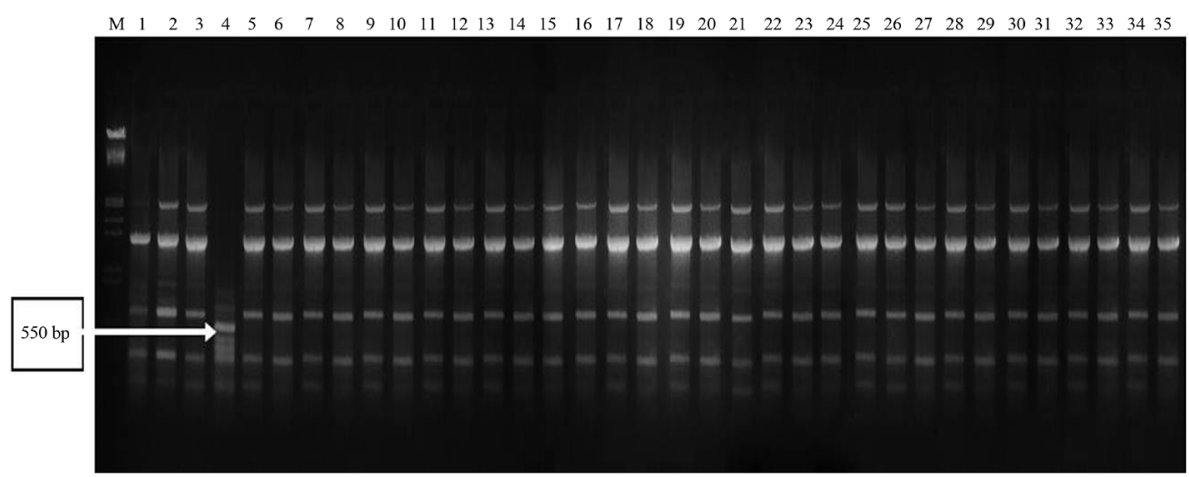

(d)

Figure 1. RAPD profiling of 35 cluster bean genotypes (a) with primer RP-3; (b) with primer RP-9; (c) with primer RP-19; (d) with primer IS-8 (lane1-35), Lane M- Lamda EcoR1/Hind III double digested. 
Table 4. Eluted fragments from RAPD and ISSR primers.

\begin{tabular}{cccccc}
\hline Sr. no. & Primer No. & Genotype & Size & Fragment type & Conc. of eluted band (ng/pl) \\
1. & RP-3 & RGC-1003 & $1000 \mathrm{bp}$ & Polymorphic & 142.5 \\
2. & RP-9 & RGC-1031 & $650 \mathrm{bp}$ & Region specific & 46.8 \\
3. & RP-19a & RGC-1002 & $1100 \mathrm{bp}$ & Polymorphic & 22.6 \\
4. & RP-19b & RGC-1003 & $1200 \mathrm{bp}$ & Polymorphic & 20.1 \\
5. & IS-8 & RGC-1031 & $550 \mathrm{bp}$ & Genotype specific & 55.6 \\
\hline
\end{tabular}

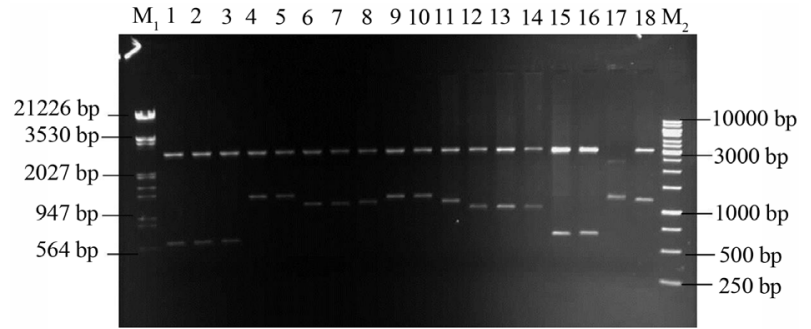

Figure 2. $\mathrm{M}_{1}$-Lamda EcoR1/Hind III double digested, $\mathrm{M}_{2}-1 \mathrm{~kb}$ Ladder, Lane 1-18- Restriction digestion of plasmid isolated from different clones.

eluted fragment. All sequences were analyzed with the help of BioEdit software and sequences from different plasmids were used to form final contig of each fragment. Out of five fragments, three were sequenced completely and in these sequences the nucleotides at both ends of the sequences obtained matched completely with the RAPD primers and ISSR primer (Figures 3(a)-(e)). Two fragments were sequenced partially and RAPD primer sequence was present only at one end. But no homology was found between the sequenced marker fragments and known sequences in the NCBI database using BLAST.

From four RAPD and one ISSR clones, four pairs of specific primers were designed for each band to amplify different sizes of fragments (Table 5). Fragment eluted from RAPD primer RP-3 (1000 bp) was sequenced partially (551 bp) in all three triplicates. Among all 4 primers designed from this sequence SCAR-4 primer with maximum product size amplified smaller region (359 bp) and generated amplicon which were present in all the genotypes at same location (Figure 4(a)). SCAR markers were generally a dominant marker. Each marker amplified one fragment; however, there were other cases where one marker produced more than one fragment. However, SCAR-1 (225 bp), SCAR-2 (137 bp) and SCAR-3 (226 bp) generated multiple bands and were not of any use.

One region specific band eluted from RAPD primer (RP-9, 650 bp) was almost fully sequenced (601 bp). SCAR-8 (573 bp) showed region specific band in genotypes of Rajasthan which is considered as region specific marker and showed polymorphism among genotypes of
Rajasthan (Figure 4(b)). Other 3 primers deigned from this sequence amplified 2 and 3 fragments and the polymorphism of the SCAR amplification was not similar to those of the original RAPD amplification.

Polymorphic fragments from RAPD primer RP-19 (1100 bp and $1250 \mathrm{bp)}$ were sequenced completely (1101 bp and $1251 \mathrm{bp})$. Among all designed primer for these fragments, SCAR-12 (1020 bp) and SCAR-16 (1080 bp) having maximum product size amplified similar polymorphism in all genotypes for these fragments (Figures 4(c) and (d)). Remaining SCAR primers i.e. SCAR-6, SCAR-7, SCAR-9, SCAR-11 and SCAR-15 did not show amplification with all genotypes.

From ISSR primer IS-8, one genotype specific band (550 bp) was eluted from RGC-1031. This fragment was sequenced completely (551 bp) and 4 primers were deigned from this sequence. Only SCAR-20 having product size $513 \mathrm{bp}$ was found suitable to infer specificity for a genotype from Rajasthan (RGC-1031) and successfully amplified the respective band (Figure 4(e)). All other primers SCAR-17 (277 bp), SCAR-18 (276 bp) and SCAR-19 (95 bp) showed multiple bands or no amplification.

\section{DISCUSSION}

With the rapid development of modern agricultural biotechnology, molecular markers have been widely used in molecular breeding, including molecular marker assisted selection $[23,24]$, variety identification, molecular mapping [25] and so on. In present study, a great range of diversity was observed in cluster bean genotypes using both RAPD and ISSR markers. However, less number of ISSRs found more informative over 20 RAPD primers. The ability of ISSRs in detecting high polymorphism compared to RAPD is well known and observed by a number of studies [26,27]. Despite of the simplicity and rapidity of RAPD and ISSRs, a few technical disadvantages associated with these markers have decreased their fidelity as genetic markers and prevented their widespread use in recent years. Therefore, the SCAR marker system was introduced in order to increase the reproducibility of polymorphisms and specificity. SCAR markers are powerful tool for identification of hybrid [28], 


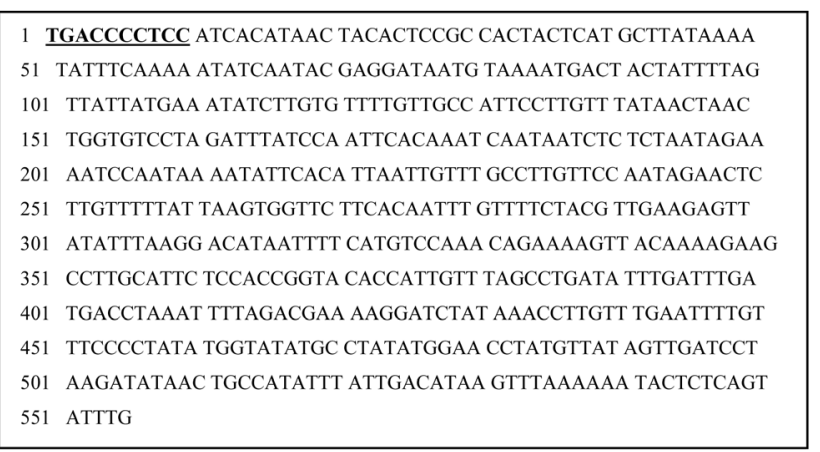

(a)

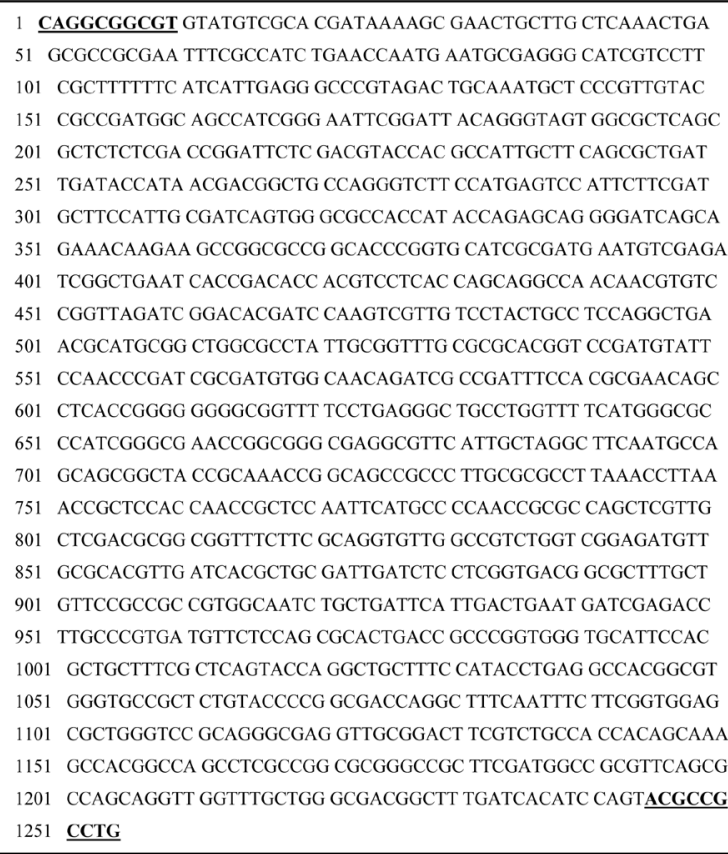

(c)

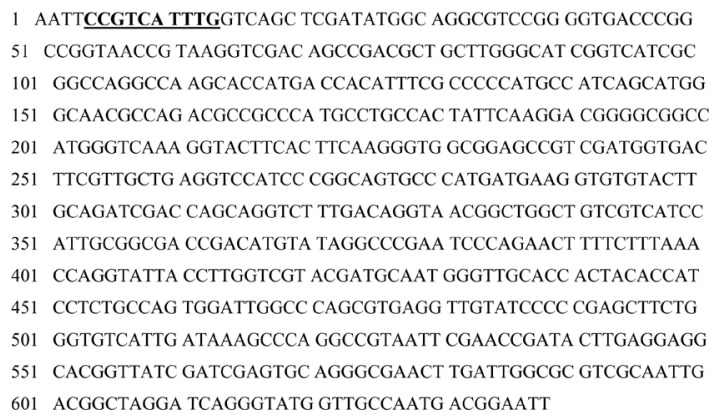

(b)

$\begin{array}{ll}1 & \text { CAGGCGGCGT GAAGCAAAGG CAGAGACAAG GTGTGGTTGT CCTGCAAGAT } \\ 51 & \text { TTCGTGTGAA TTTTGATCCA CGAACGCAGC GTTGGCACAC ATCTTTTTT } \\ 101 & \text { CGTGATGACC ACAACCATGA TTTAATGATT CAGAGCTTGA CGCCAATGTT } \\ 151 & \text { TCCCGCTCAT AGGGTGATGA CTGATTCTGA CATTTTACAA ATGATAGTAT } \\ 201 & \text { GCGCAGAGTT GGTATTAGCA CTCCCCAAAT ATTTGGGGCA TTGGCACAAC } \\ 251 & \text { AATCACGGGG CTATCACAAC GTTCGTTTCA AAAAGCGGGA TATGTATAAT } \\ 301 & \text { GAAATTGACA AGCAAAGACA TTGCAATTG TCTGATGCAG CGGGTGCTTT } \\ 351 & \text { GATGTTTCTA CGTGATAAAA AACCAAGAGA TAAAGATCTA TTCTTTTTGC } \\ 401 & \text { CAAACAGTTG ACGACGAACG AAGACTAGAG CACTTAATGT GGTCCTGATG } \\ 451 & \text { GGCATAACCA GAGAGATTAC AAATGCCTTC AGTGATGTGC TTGCTTTTGA } \\ 501 & \text { CGCAACGTAT GGTAAGAACA AATACTCCTT GCCACTAGTT GTTTATTCTG } \\ 551 & \text { GTGTTAATCA TCACAATCAG TCAGTTATAT TTGCTAGTGC CCTTATTGCA } \\ 601 & \text { AATGAGACAG AAGAGACATA TATCTGGTTA CTTGAACAAT TTTTGGTGGT } \\ 651 & \text { AATGAAAGGA AAACAACCAT TATTGGTGAT TACAAATGGT GACAATGCAA } \\ 701 & \text { TGAAGAATGC CATATCGAAA GTTTTTCTAG ATGCTTATCA CCGTTTATGC } \\ 751 & \text { TCTTGGCACT TGTCACGCAA TGCAAATACT AACATAAAGA ATCGAAGTTT } \\ 801 & \text { TGTCATGGAG TTTGAGCAGT TAATGTATGG TGAATACAAT ATTGGTGAAT } \\ 851 & \text { TTGGGAGAAA ATGGACTGAG TTGGTGCAC GACATGGGCT TGAGAACAAT } \\ 901 & \text { GTATGGGTAA ACAGCATGTA TGAGAAGAGG AAGATGTGGG CTACAACATA } \\ 951 & \text { CATTCGCGGT AAATTCTTTG TTGGTTTTAG AACAACTTCA CGTTGTGAGG } \\ 1001 & \text { GGTTACATTT AGAGATTGGA AATTTTGTTC TCTCACGCTA TAACTTGGTG } \\ 1051 & \text { GAGTTTTTGC AACATTTAAG TCGTTATGTT GAATACATGC GTCTTAGAGA } \\ 1101 & \text { GCGTGACGCC GCCTG }\end{array}$

(d)

\begin{abstract}
1 Gagagagaga GaGaGaCCAA ACGGACACAG CTTGCTCTGT GTCTATGTTT 51 TGTTTCAACT TTTGCCCGGC ATCTGTGTTC CAGGATTTGT CTCTTCAACC 101 AAGAGGAAAC TCTCCGTTTT CTTTCTAGAG ATTATTCAAA AAAATTGTTC 151 AAATGTTCCC AGTTTTCTCT AAAAATAATT CAAATGAAAA TCTGACAGAT 201 TCTGAATCTG TTCGTTGAAC AATTCGTTCG TCACACTTTT AATATCGATG 251 ATCGATTCGT TCATCACTAT GATTGTCTAT GACAGTGGCA AAGTTGGCAA 301 TGGACGAATG GCAGTATAGT ATTTGTTTAG GACTGCCAAA ACTAGCAAAA 351 TTTTCGGCGC TCATCTGTAT GATGTACAAA ATATTTTTTT CGAAATTGAT 401 TTGTCGAATT TAAAAAAATA CAAAATATCA TTTTCGAAAA TGTTCGATTT 451 CGAATTGTGT CTCACCCTGT GAATATTAAT AACGATTTCT CTCTCTCTCT 501 CTCTTTCTCT CCTTTGCTCG TTTAATTCGC GGAAGGGGTA AACAGGCACT 551 AGATTTCTCC TTCCTACTTT GTCTCTCTCT CTCTCTC
\end{abstract}

Figure 3. DNA sequence of eluted fragments from RAPD (a) RP-3; b) RP-9; c) RP-19a; d) RP-9b) and ISSR (E, IS-8).

genotype [29], specific genes [30] as well as for sex diagnosis [31], and marker assisted selection (MAS) [32, 33].

First of all, the RAPD and ISSR profiles were careful- ly observed to select amplicons which were reproducible over repetition and useful in molecular marker based studies. Using RAPD and ISSR profile, 3 SCARs for polymorphic RAPD markers, one for genotype specific 


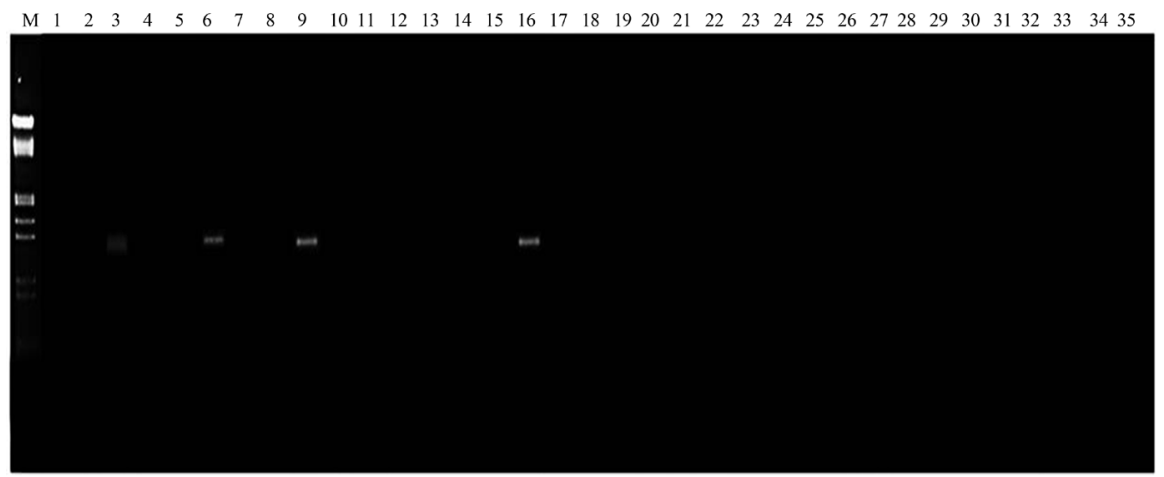

(a)

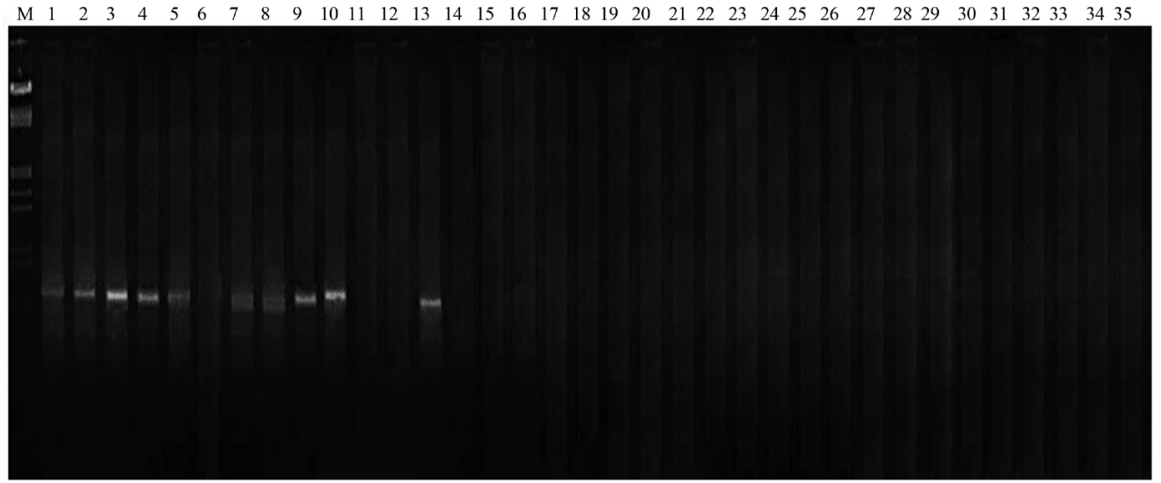

(b)

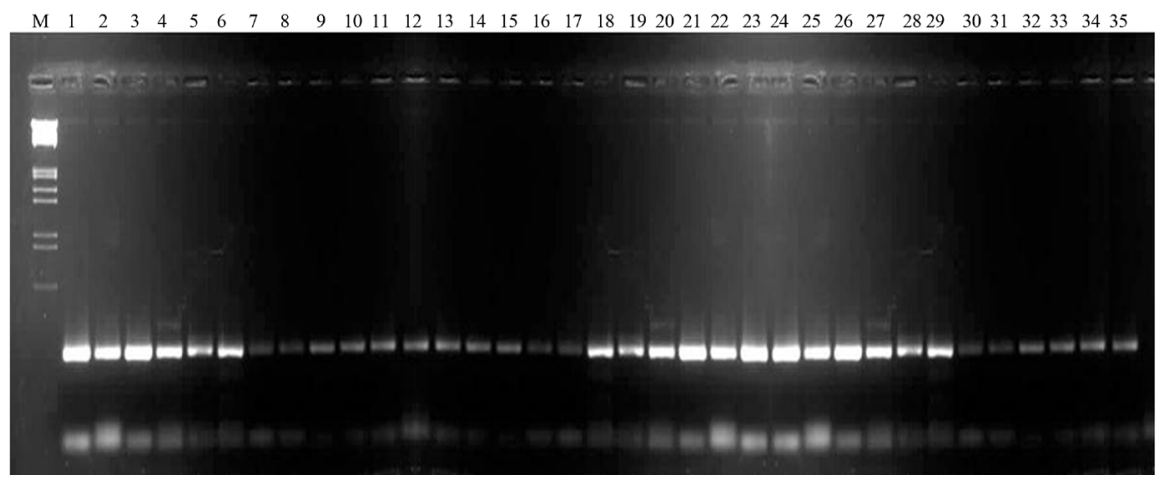

(c)

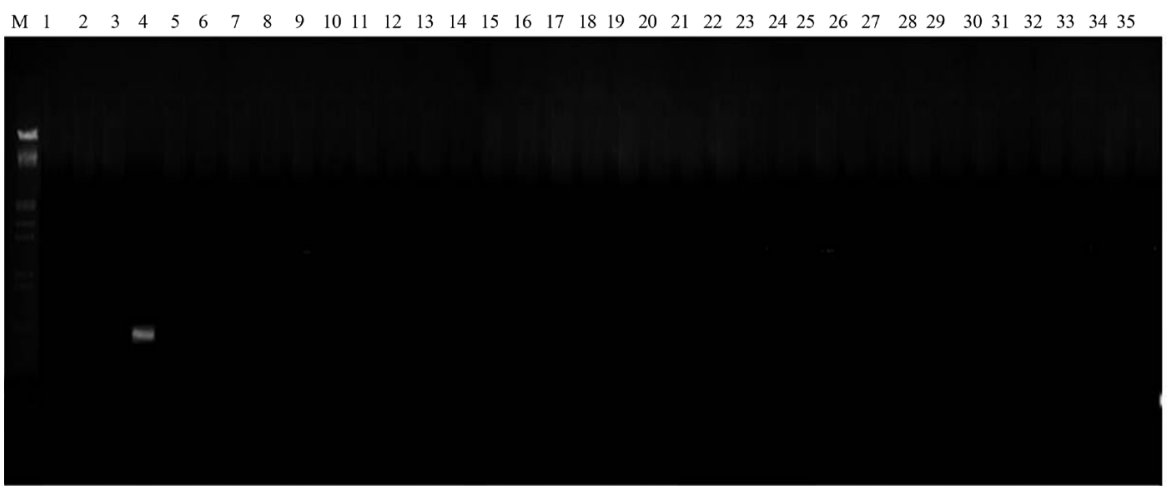

(d)

Figure 4. Amplification of 35 cluster bean genotypes (a) with primer SCAR-4 (359 bp); (b) with primer SCAR-8 (573 bp); (c) with primer SCAR-12 (1020 bp); (d) with primer SCAR-20 (513 bp), Lane M- Lamda EcoR1/ Hind III double digested. 
Table 5. SCAR primers.

\begin{tabular}{|c|c|c|c|c|c|}
\hline RAPD/ISSR Primers & SCAR primers & Sequence (5'-3') & $\operatorname{Tm}\left({ }^{\circ} \mathrm{C}\right)$ & $\% G C$ & Product Size \\
\hline \multirow{4}{*}{ RP-3 } & SCAR-1 & $\begin{array}{l}\text { F- TACACTCCGCCACTACTCAT } \\
\text { R- CTATTGGAACAAGGCAAACA }\end{array}$ & $\begin{array}{l}55.8 \\
56.3\end{array}$ & $\begin{array}{l}50 \\
40\end{array}$ & 225 bp \\
\hline & SCAR-2 & $\begin{array}{l}\text { F- TGTTTGCCTTGTTCCAATAG } \\
\text { R- GAGAATGCAAGGCTTCTTTT }\end{array}$ & $\begin{array}{l}56.3 \\
56.3\end{array}$ & $\begin{array}{l}40 \\
40\end{array}$ & 137 bp \\
\hline & SCAR-3 & $\begin{array}{l}\text { F- CTACACTCCGCCACTACTCA } \\
\text { R- CTATTGGAACAAGGCAAACA }\end{array}$ & $\begin{array}{l}56.5 \\
56.3\end{array}$ & $\begin{array}{l}55 \\
40\end{array}$ & 226 bp \\
\hline & SCAR-4 & $\begin{array}{l}\text { F- GACCCCTCCATCACATAACT } \\
\text { R- GAATGCAAGGCTTCTTTTGT }\end{array}$ & $\begin{array}{l}56.3 \\
57.1\end{array}$ & $\begin{array}{l}50 \\
40\end{array}$ & 359 bp \\
\hline \multirow{4}{*}{ RP-9 } & SCAR-5 & $\begin{array}{l}\text { F- CATGGGTCAAAGGTACTTCA } \\
\text { R-AAGAAAAGTTCTGGGATTCG }\end{array}$ & $\begin{array}{l}56 \\
56\end{array}$ & $\begin{array}{l}45 \\
40\end{array}$ & 197 bp \\
\hline & SCAR-6 & $\begin{array}{l}\text { F- CAGGTCTTTGACAGGTAACG } \\
\text { R-AAGAAAAGTTCTGGGATTCG }\end{array}$ & $\begin{array}{c}55.8 \\
56\end{array}$ & $\begin{array}{l}50 \\
40\end{array}$ & 83 bp \\
\hline & SCAR-7 & $\begin{array}{l}\text { F- CGAATCCCAGAACTTTTCTT } \\
\text { R- TATCAATGACACCCAGAAGC }\end{array}$ & $\begin{array}{c}56 \\
56.1\end{array}$ & $\begin{array}{l}40 \\
45\end{array}$ & 137bp \\
\hline & SCAR-8 & $\begin{array}{l}\text { F- GGTAACCGTAAGGTCGACAG } \\
\text { R- GCAACCATACCCTGATCCTA }\end{array}$ & $\begin{array}{l}57.2 \\
57.5\end{array}$ & $\begin{array}{l}55 \\
50\end{array}$ & 573 bp \\
\hline \multirow{4}{*}{ RP-19 a } & SCAR-9 & $\begin{array}{l}\text { F- GTATGTCGCACGATAAAAGC } \\
\text { R- CAGTAGGACAACGACTTGGA }\end{array}$ & $\begin{array}{c}56 \\
56.3\end{array}$ & $\begin{array}{l}45 \\
50\end{array}$ & 478 bp \\
\hline & SCAR-10 & $\begin{array}{l}\text { F- AGCGCTGATTGATACCATAA } \\
\text { R- CATTGAAGCCTAGCAATGAA }\end{array}$ & $\begin{array}{l}55.9 \\
56.6\end{array}$ & $\begin{array}{l}40 \\
40\end{array}$ & 456 bp \\
\hline & SCAR-11 & $\begin{array}{l}\text { F- TCCAAGTCGTTGTCCTACTG } \\
\text { R- GAGCGGTTTAAGGTTTAAGG }\end{array}$ & $\begin{array}{l}56.3 \\
55.8\end{array}$ & $\begin{array}{l}50 \\
45\end{array}$ & 289 bp \\
\hline & SCAR-12 & $\begin{array}{l}\text { F- GTATGTCGCACGATAAAAGC } \\
\text { R- GAAAGCAGCCTGGTACTGAG }\end{array}$ & $\begin{array}{c}56.01 \\
57.7\end{array}$ & $\begin{array}{l}45 \\
55\end{array}$ & 1020 bp \\
\hline \multirow{4}{*}{ RP-19 b } & SCAR-13 & $\begin{array}{l}\text { F- GCTATCACAACGTTCGTTTC } \\
\text { R- AGCATAAACGGTGATAAGCA }\end{array}$ & $\begin{array}{c}55.9 \\
56\end{array}$ & $\begin{array}{l}45 \\
40\end{array}$ & 492 bp \\
\hline & SCAR-14 & $\begin{array}{l}\text { F- GGTGCTTTGATGTTTCTACG } \\
\text { R- CAAGTGCCAAGAGCATAAAC }\end{array}$ & $\begin{array}{l}55.9 \\
56.1\end{array}$ & $\begin{array}{l}45 \\
45\end{array}$ & 420 bp \\
\hline & SCAR-15 & $\begin{array}{l}\text { F- GATAGTATGCGCAGAGTTGG } \\
\text { R-AGCATAAACGGTGATAAGCA }\end{array}$ & $\begin{array}{l}56 \\
56\end{array}$ & $\begin{array}{l}50 \\
40\end{array}$ & 559 bp \\
\hline & SCAR-16 & $\begin{array}{l}\text { F- AGACAAGGTGTGGTTGTCCT } \\
\text { R- CGCTCTCTAAGACGCATGTA }\end{array}$ & $\begin{array}{c}57 \\
56.9\end{array}$ & $\begin{array}{l}50 \\
50\end{array}$ & 1080 bp \\
\hline \multirow{4}{*}{ IS-8 } & SCAR-17 & $\begin{array}{l}\text { F- TGTGTTCCAGGATTTGTCTC } \\
\text { R- TTTTGCTAGTTTTGGCAGTC }\end{array}$ & $\begin{array}{c}56 \\
55.8\end{array}$ & $\begin{array}{l}45 \\
40\end{array}$ & 277 bp \\
\hline & SCAR-18 & $\begin{array}{l}\text { F- TCTGTGTTCCAGGATTTGTC } \\
\text { R- TGCTAGTTTTGGCAGTCCTA }\end{array}$ & $\begin{array}{c}56 \\
56.2\end{array}$ & $\begin{array}{l}45 \\
45\end{array}$ & 276 bp \\
\hline & SCAR-19 & $\begin{array}{l}\text { F- ACACAGCTTGCTCTGTGTCT } \\
\text { R-AAACGGAGAGTTTCCTCTTG }\end{array}$ & $\begin{array}{l}56.1 \\
56.1\end{array}$ & $\begin{array}{l}50 \\
45\end{array}$ & 95 bp \\
\hline & SCAR-20 & $\begin{array}{l}\text { F- GAGAGAGACCAAACGGACAC } \\
\text { R-AAACGAGCAAAGGAGAGAAA }\end{array}$ & $\begin{array}{l}57.2 \\
56.8\end{array}$ & $\begin{array}{l}55 \\
40\end{array}$ & 513 bp \\
\hline
\end{tabular}

ISSR marker, and one for region specific RAPD marker were designed. Out of 20 primer pairs, only 5 generated true to type amplicons and were further selected for study. The inability to convert the RAPDs to SCARs has been reported in other studies where a high number of polymorphisms were identified through RAPD analysis and only a small subset of these were convertible to SCAR markers [29,34].

It has been argued that RAPD polymorphisms might be the result of mismatch at the priming sites, rather than sequence divergence or structural re-arrangements [35]. The difference in polymorphism between RAPD and the SCAR markers or the lost polymorphism of converted
SCAR markers was also shown in the studies of $\mathrm{cu}-$ cumber [36], grapevine [37], wheat [38], Populus deltoides [39] and common carp [23]. RAPD polymorphism was mostly caused by mismatches on the primer sites or molecular rearrangement. SCAR polymorphism originated from the variations within the amplified fragment [40].

In the present study, it is also possible that the differences in the polymorphism between RAPD and SCAR markers or the lost polymorphism of converted SCAR markers are mainly because of the complex structure of the cluster bean genome and the highly repetitive sequences within the genome. Hence, it is relatively diffi- 
cult to detect reliable polymorphic bands in the cluster bean genome only by using the RAPD technique, and then converting them into stable SCAR markers. Some high polymorphic markers, such as the amplified fragment length polymorphism (AFLP), simple sequence repeats (SSR), and the sequence-related amplified polymorphism (SRAP) could be considered to be used or jointly used in future studies.

This is the first time that we have introduced SCARs to find more specific information using RAPD and ISSR profiles. However, the development of SCARs is more cumbersome and their specificity is trustworthy. In our study, one genotype specific SCAR for RGC-1031, one of the tolerant genotype of Rajasthan against Macrophomina phaseolina [41] could be used to prove identity of the genotype as well for its genetic purity assessment. Another SCAR was selected due to its specificity for cluster bean genotypes from Rajasthan which might be important for population admixture studies. Although the SCARs generated in present study were not developed for any agronomic characteristics, the methodology could be harnessed in further studies in tagging genes of economic importance without validation steps. The current set of SCARs has limited application in diversity analysis and identification of cluster bean genotypes.

\section{REFERENCES}

[1] Anonyms (2006) “Guar Production” Vernon Agricultural Research \& Extension Center. Texas A\&M University.

[2] Pathak, R., Singh, M. and Henry, A. (2011) Genetic diversity and interrelationship among cluster bean (Cyamopsis tetragonoloba) genotypes for qualitative traits. Indian journal of Agricultual Science, 81, 402-406.

[3] Gresta, F., Sortinob, O., Santonocetoa, C., Issi, L., Formanticic, C. and Galante, Y.M. (2013). Effects of sowing times on seed yield, protein and galactomannans content of four varieties of guar (Cyamopsis tetragonoloba L.) in a Mediterranean environment. Industrial Crops and Products, 41, 46-52.

http://dx.doi.org/10.1016/j.indcrop.2012.04.007

[4] Chopra, D.P. and Bhandari, D.C. (1989) Plant genetic resources: Collection and promising introductions for arid and semi-arid regions. Indian Journal of Plant Genetic Resources, 2, 60-63.

[5] Shabarish, R.P., Dharmatti, P.R., Shashidhar, T.R., Patil, R.V. and Patil, B.R. (2012) Genetic variability studies in cluster bean [Cyamopsis tetragonoloba (L.) Taub]. Karnataka Journal of Agricultural Science, 25, 108-111.

[6] Brahmi, P., Bhat, K.V. and Bhatnagar, A.K. (2004) Study of allozyme diversity in guar [Cyamopsis tetragonoloba (L.) Taub] germplasm. Genetic Resources and Crop Evolution, 51, 735-746.

http://dx.doi.org/10.1023/B:GRES.0000034581.71299.8b

[7] Rao, L.S., Usha Rani, P., Deshmukh, P.S., Kumar, P.A. and Panguluri, S.K. (2007) RAPD and ISSR fingerprint- ing in cultivated chickpea (Cicer arietinum L.) and its wild progenitor Cicer reticulatum Ladizinsky. Genetic Resources and Crop Evolution, 54, 1235-1244. http://dx.doi.org/10.1007/s10722-006-9104-6

[8] Kumar, V. and Sharma, S.N. (2009) Assessment of genetic diversity of sesame (Sesamum indicum L.) genotypes using morphological and RAPD markers. Indian Journal of Genetics and Plant Breeding, 69, 209-218.

[9] Masuzaki, S., Yaguchi, S., Yamauchi, N. and Shigyo, M. (2007) Morphological characterization of Allium multiple alien addition lines reveals chromosomal locations of gene(s) related to bulb formation in Allium cepa. The Journal of Horticultural Science and Biotechnology, 82, 393-396.

[10] Paran, I. and Michelmore, R.W. (1993) Development of reliable PCR based markers linked to downy mildew resistance genes in lettuce. Theoretical and Applied Genetics, 85, 985-993. http://dx.doi.org/10.1007/BF00215038

[11] Ferriol, M., Pic, B. and Nuez, F. (2003) Genetic diversity of a germplasm collection of Cucurbita pepo using SRAP and AFLP markers. Theoretical and Applied Genetics, 107, 271-282. http://dx.doi.org/10.1007/s00122-003-1242-Z

[12] Sun, S.J., Gao, W., Lin, S.Q., Zhu, J., Xie, B.G. and Lin, Z.B. (2006) Analysis of genetic diversity in Ganoderma population with a novel molecular marker SRAP. Applied Microbiology and Biotechnology, 72, 537-543. http://dx.doi.org/10.1007/s00253-005-0299-9

[13] Zheng, X.Y., Wang, Y.J., Song, S.H., Li, L. and Yu, S.C. (2002) Identification of heat tolerance linked molecular markers of Chinese cabbage (Brassica campestris L. sp Pekinensis). Agricultural Sciences in China, 1, 786-791.

[14] Yi, Y.J., Liu, H.Y., Huang, X.Q., An, L.Z., Wang, F. and Wang, X.L. (2007) Development of molecular markers linked to the wheat powdery mildew resistance gene Pm $4 b$ and marker validation for molecular breeding. Plant Breeding, 127, 116-120. http://dx.doi.org/10.1111/j.1439-0523.2007.01443.x

[15] Sun, Z.D., Wang, Z.N., Tu, J.X., Zhang, J.F., Yu, F.Q., McVetty, P.B.E. and Li, G. (2007) An ultra-dense genetic recombination map for Brassica napus, consisting of 13551 SRAP markers. Theoretical and Applied Genetics, 114, 1305-1317. http://dx.doi.org/10.1007/s00122-006-0483-Z

[16] Yu, J.W., Yu, S.X., Lu, C.R., Wang, W., Fan, S.L., Song, M.Z., Lin, Z.X., Zhang, X.L. and Zhang, J.F. (2007) High-density linkage map of cultivated allotetraploid cotton based on SSR, TRAP, SRAP and AFLP markers. Journal of Integrative Plant Biology, 49, 716-724. http://dx.doi.org/10.1111/j.1744-7909.2007.00459.x

[17] Punia, A., Arora, P., Yadav, R. and Chaudhury, A., (2009) Optimization and inference of PCR conditions for genetic variability studies of commercially important cluster bean varieties by RAPD analysis. Asian Pacific Journal of Molecular Biology and Biotechnology, 17, 33-38.

[18] Punia, A., Yadav, R., Arora, P. and Chaudhary, A. (2009) Molecular and morphophysiological characterization of superior Cluster bean (Cyamopsis tetragonoloba) varieties. Journal of Crop Science and Biotechology, 12, 143- 
148. http://dx.doi.org/10.1007/s12892-009-0106-8

[19] Pathak, R., Singh, S.K., Singh, M. and Henry, A. (2010) Molecular assessment of genetic diversity in cluster bean (Cyamopsis tetragonoloba) genotypes. Journal of Genetics, 89, 243-246. http://dx.doi.org/10.1007/s12041-010-0033-y

[20] Doyle, J.J. and Doyle, J.L. (1990) Isolation of plant DNA from fresh tissue. Focus, 12, 13-15.

[21] Rohlf, F.J. (1997) NTSYS-Pc. Numerical taxonomy and multivariate analysis system version 2.2e. Exeter Software, New York.

[22] Tessier, C., David, J., This, P., Boursiquot, J.M. and Charrier, A. (1999) Optimization of the choice of molecular markers for varietal identification in Vitis vinifera L. Theoretical and Applied Genetics, 98, 171-177. http://dx.doi.org/10.1007/s001220051054

[23] Gao, F.Y., Lu, X.J., Wang, W.M., Sun, S.S., Li, Z.H., Li, H. and Ren, G.J. (2009) Trait-specific improvement of a cytoplasmic male-sterile line using molecular marker-assisted selection in rice. Crop Science, 49, 99-106. http://dx.doi.org/10.2135/cropsci2008.03.0168

[24] Hashemi, S.H., Mirmohammadi-Maibody, S.A.M., Nematzadeh, G.A. and Arzani, A. (2009) Identification of rice hybrids using microsatellite and RAPD markers. African Journal of Biotechnology, 8, 2094-2101.

[25] Wang, J.F., Yang, W.H., Kuang, M., Xu, H.X., Wang, Y.Q., Zhou, D.Y. and Feng, X.A. (2009) Research on fingerprint mapping and purity identification of cotton varieties. China Cotton, 36, 16-24.

[26] Nagaoka, T. and Ogihara, Y. (1997) Applicability of intersimple sequence repeat polymorphisms in wheat for use as DNA markers in comparison to RFLP and RAPD markers. Theoretical and Applied Genetics, 94, 597-602. http://dx.doi.org/10.1007/s001220050456

[27] Ajibade, S.R., Weeden, N.F. and Chite, S.M. (2000) Inter-simple sequence repeats analysis of genetic relationships in the genus Vigna. Euphytica, 111, 47-55. http://dx.doi.org/10.1023/A:1003763328768

[28] Weng, C., Kubisiak, T.L. and Stine, M. (1998) SCAR markers in a long leaf pine x slash pine F1 family. Forest Genetics, 5, 239-247.

[29] Bautista, R., Crespillo, R., Canovas, F.M. and Claros, M.G. (2002) Identification of olive tree cultivars with SCAR markers. Euphytica, 129, 33-41. http://dx.doi.org/10.1023/A:1021528122049

[30] Arnedo-Andres, M.S., Gil-Ortega, R., Luis-Arteaga, M. and Hormaza, J.I. (2002) Development of RAPD and SCAR markers linked to the Pvr4 locus for resistance to PVY in pepper (Capsicum annuum L.). Theoretical and Applied Genetics, 105, 1067-1074. http://dx.doi.org/10.1007/s00122-002-1058-2

[31] Deputy, J.C., Ming, R., Ma, H., Liu, Z., Fitch, M.M.M., Wang, M., Manshardt, R. and Stiles, J.I. (2002) Molecular markers for sex determination in papaya (Carica pa- paya L.). Theoretical and Applied Genetics, 106, 107111.

[32] Cairo, C.A., Stein, J., Delgado, L., Bortolotti, S., Guelman, S.A., Ortiz, J.P.A. and Morandi, E.N. (2002) Tagging the juvenile locus in soybean [Glycine max (L.) Merr.] with molecular markers. Euphytica, 124, 387-395. http://dx.doi.org/10.1023/A:1015767623038

[33] Lecouls, A.C., Bergougnoux, V., Rubio-Cabetas, M.J., Bosselut, N., Voisi, R., Poessel, J.L., Faurobert, M., Bonnet, A., Salesses, G., Dirlewanger, E. and Esmenjaud, D. (2004) Marker-assisted selection for the wide spectrum resistance to root-knot nematodes conferred by the Ma gene from myrobalan plum (Prunus cerasifera) in inter-specific Prunus material. Molecular Breeding, 13, 113-124.

http://dx.doi.org/10.1023/B:MOLB.0000018758.56413.cf

[34] Yuskianti, V. and Shiraishi, S. (2010) Developing SNP markers and DNA typing using multiplexed Single Nucleotide Primer Extension (SNuPE) in Paraserianthes falcataria. Breeding Science, 60, 87-92.

http://dx.doi.org/10.1270/jsbbs.60.87

[35] Hernández, P., Martin, A. and Dorado, G. (1999) Development of SCARs by direct sequencing of RAPD products: A practical tool for the introgression and markerassisted selection of wheat. Molecular Breeding, 5, 245253. http://dx.doi.org/10.1023/A:1009637928471

[36] Horejsi, T., Box, J.M. and Staub, J.E. (1999) Efficiency of randomly amplified polymorphic DNA to sequence characterized amplified region marker conversion and their comparative polymerase chain reaction sensitivity in cucumber. Journal of American Society of Horticulture Science, 124, 128-135.

[37] Vidal, J.R., Delavault, P., Coarer, M. and Defontaine, A. (2000) Design of grapevine (Vitas vinifera L.) cultivarspecific SCAR primers for PCR fingerprinting. Theoretical and Applied Genetics, 101, 1194-1201. http://dx.doi.org/10.1007/s001220051597

[38] Yan, N.H., Chen, J., Ma, X.R., Deng, G.B. and Yu, M.Q. (2003) Conversion of RAPD marker to SCAR marker of wheat cereal root-knot nematode-resistant gene Rkn-mnl. Chinese Journal of Applied Environmental Biology, 9, 250255.

[39] Zhang, Y.M., Pan, H.X., Zhang, B., Wang, M.X. and Huang, M.R. (2007) Development of SCAR markers linked to resistance locus of black spot disease in Populus deltoides. Journal of Nanjing University, 31, 15-18.

[40] Bodénès, C., Joandet, S., Laigret, F. and Kremer, A. (1997) Detection of genomic regions differentiating two closely related oak species Quercus petraea (Matt.) Liebl. and Quercusrobur L. Heredity, 78, 433-444. http://dx.doi.org/10.1038/hdy.1997.67

[41] Chitale, K. and Tak, S.K. (2003) Management of charcoal rot of cluster bean. In: Henary, A., Ed., Advances in Arid Legume Research, Scientific Publishers, India, 412-414. 